[Philips, D., Roddick, S., \& Weenink, M. (2001). The Strategic Research Initiative Literature Reviews. New Zealand Annual Review of Education, 10, 39-70]

\section{The Strategic Research Initiative Literature Reviews}

\author{
DAVID PHILIPS, SUSANNAH RODDICK AND MELISSA \\ WEENINK
}

\section{Abstract:}

This article describes the process for developing the Ministry of Education's "Strategic Research Initiative", and the thinking behind it, in particular the literature reviews commissioned by the Ministry in 1999 and published in 2000. Each of the reviews is briefly described to indicate some of the key themes which, along with consultation with the research community, are a means of helping Ministry staff to identify potential priorities for strategic research.

$\mathrm{T}$ owards the end of 2000, the Ministry of Education released a series of literature reviews, conducted as part of its Strategic Research Initiative (SRI). This initiative was intended to help identify the Ministry's research priorities for the next three to five years; align policy development and research more closely; and strengthen the Ministry's information base. An important outcome of this exercise was to ensure that decisions made about priorities for research were based on a more strategic approach to commissioned research, one which more closely reflected policy needs.

The literature reviews covered seven areas, with an emphasis on their impact on education outcomes: family and community resources; early childhood education; curricula, assessment, pedagogy; school governance, organisation and management; school resourcing; postcompulsory education; and enterprise-based education and training. A review of the role of peer effects in students' learning was also commissioned. Subsequently, further reviews on issues related to human resources, the quality of post-compulsory education and training and participation, were commissioned to supplement these.
40 David Philips, Susannah Roddick and Melissa Weenink

This article provides an account of the process leading up to the release of the literature reviews, and their purpose, describes the content of each literature review, and looks to the future.

\section{Background to the Process of Developing the Reviews}

In late 1997, the Strategic Management Group in the Ministry of Education proposed that there was a need for a more strategic approach towards commissioning research that would inform policy planning and development. In late 1998, the Strategic Research Initiative (SRI) was taken, with the aim of helping to identify the Ministry's research priorities for the next three to five years. The SRI was designed to ensure that current policy work continued to be underpinned by sound research, and that the Ministry's strategic information base would enable it to anticipate future policy issues.

Initially, two sessions were held with policy staff in the Ministry of Education to determine which broad themes should be the focus of research. Some of the issues considered were: whether the research priorities should reflect a functional/sectoral approach (i.e., school, early childhood, post compulsory) or some other thematic approach; the role of research on Maori education issues; and whether a particular focus should be placed on students at risk. These sessions also covered the criteria by which areas should be prioritised. One clear set of criteria was related to the priorities of the Ministry of Education Strategic Business Plan - lifting achievement of all students and also closing the achievement gap between different groups of students. However, other criteria were also discussed, such as durability and feasibility, and broad areas for research were identified. As a result of these research discussions, a stock-take of recent research was proposed, and the research topics were confirmed.

The Ministry commissioned a suite of "state-of-the-art" literature reviews. The Ministry recognised that it needed an up-to-date understanding of developments in a range of areas in order to ensure that the most current thinking and developments in the research literature informed its research priority-setting process. In particular, it was recognised that it was necessary to take a broad view of the literature, and not focus on a narrow range of influences on educational achievement and outcomes.

The purpose of the literature reviews was to:

- ensure that the most current thinking and developments in the 
research literature informed the Ministry's research priority-setting process; and

- identify key gaps in the knowledge base, and the nature of research that might address those gaps.

Developing a more comprehensive understanding of the current knowledge base was strongly linked to the effort by the Ministry to take a broader view of the influences on education outcomes. In particular, the knowledge base needed to assist the Ministry to work towards:

- achieving better articulation of effective practices, student achievement, and education strategy;

- improving educators' professional capability and practices,

- improving the capability of educational providers to assess and enhance the overall effectiveness of their teaching strategies and practices;

- enhancing how local networks of educational providers and their communities might work together effectively;

- ensuring better integration of its own research, data gathering and information sources.

To make the task manageable, a number of areas of interest were identified, although it was acknowledged that dividing the "education cake" into different slices is always a somewhat arbitrary exercise. For example, a strictly sectoral approach - early childhood, school and tertiary sectors - could be constraining, and risk missing important, over-arching issues such as workplace training or family involvement in the learning process. The approach taken was designed to reflect the Ministry's focus on influences on education outcomes in the broadest sense, beyond a more traditional institutional focus. It had to encompass the influence of families, communities, and peers on education outcomes, and also look towards the relationships between education and social policy, and the labour market and economy.

In the end, it was decided that the literature reviews should cover seven areas:

1. The Effect of Family and Community Resources on Education Outcomes

2. Early Childhood Education

3. The Effects of Curricula and Assessment on Pedagogy and on Education Outcomes
4. The Effects of School Governance, Organisation and Management on Education Outcomes

5. The Effect of School Resourcing on Education Outcomes

6. Post Compulsory Education

7. Enterprise-based Education and Training

The literature reviews were designed to focus on what the research found, as well as on what it did not find or did not examine. Reviewers were asked to critically examine the literature and to point out methodological constraints and inconsistencies. They were also asked to identify where, from their experienced eye, there were gaps. Special education was deliberately omitted, as other literature reviews were already underway in this area.

In late 1998, Ministry of Education advisory groups for the review areas were formed. These comprised the Research Division, Medium Term Strategy and other policy units. Policy involvement was crucial to strengthen the research-policy connection and identify strategic research needs for policy formulation. Each advisory group prepared a Request for Proposals covering its own area.

Given their scope, and the strategic importance that was being placed on these reviews, each Request for Proposals was critiqued by two experts in educational research (one New Zealand and one international), and subsequently revised. In early 1999, 40 New Zealand and 40 international researchers were given the opportunity to tender for the seven literature reviews. Because of the breadth of each literature review, the Ministry encouraged tenders from multidisciplinary and domestically and internationally based teams.

The advisory groups then short-listed and selected the seven successful review teams from about 35 tenders received. The advisory groups and the review teams worked through an iterative process to refine the scope and focus of the literature reviews, and the final drafts were submitted to the Ministry in the last quarter of 1999.

Because of their size and importance, the final reports were peer reviewed by New Zealand and/or international experts; and the reviewers were also invited to proffer their own views on research priorities. The peer reviews provided extensive and detailed criticisms that were found very valuable by the Ministry. Both the Ministry and the peer reviewers felt that the original review authors produced impressive work given the very demanding scope of the task and the constrained time frames. 


\section{The Literature Reviews}

The literature reviews have provided Ministry officials with important research information related to strategic and operational policy issues. They provide extensive accounts of research in their designated areas, but for the purposes of this article only a brief summary of the range and depth of topics covered, and some indication of their flavour and breadth, is provided. Specific references are excluded.

It is recommended that readers interested in detailed references obtain the original literature reviews from the Ministry of Education's Research and Evaluation (Internal) Unit. Readers should also note that this article is a presentation of the findings, not a critique of them.

Summaries of the literature reviews follow below:

The Impact of Family and Community Resources on Student Outcomes: An Assessment of the International Literature, by Thomas Nechyba, Patrick McEwan, and Dina Older-Aguilar, from Stanford University.

The primary focus of this literature review, which included international and New Zealand research, was on the family and community influences on student outcomes, with the school as a secondary focus. The relationships between various family and community influences or variables were mapped in terms of "causal channels". The main focus was on cognitive and school outcomes. The authors also investigated behavioural genetics research, and compared the relative influence over time of environmental and genetic influences.

Impact of family resources

In terms of family environment, the review examined factors traditionally thought to impact on student outcomes, such as birth order, numbers of siblings, number of girls relative to boys, and parental divorce. In the latter case, while there is a consistent negative association, the roots of this are not entirely clear - the effects of divorce might actually reflect genetic influences, home environments might be stressful prior to the dissolution of the marriage, divorce may negatively affect outcomes by reducing the family income. The review confirmed the importance of family resources for families at the lower SES levels.

Any negative impacts caused through mothers engaging in paid employment outside the home seemed likely to be temporary and dissipate by middle childhood. The review also found that quality childcare often improves the outcomes for at-risk children. Adolescent after-school care arrangements chosen by parents seem to play nolarge part in explaining differences in outcomes. Lack of supervision after school outside the home may matter, with children in unsupervised non-home environments associating with more deviant peers and demonstrating worse outcomes in school. While structured after-school programmes seem to have little (or possibly negative) impact on middle class children, evidence suggests they may improve outcomes for at-risk children, especially boys.

Family-school interactions

General enthusiasm for increased parental involvement in schools finds relatively little support in some earlier studies that report rather mixed results, but they rarely allow for potential biases introduced by particular research methods. It is too early to judge the precise nature of parental involvement effects in schools, even if the best evidence is suggestive of at least a moderate, positive impact of such involvement.

Studies of the potential of peers to affect each other within schools and classrooms are challenging to interpret. There was little evidence of school-wide peer influences from mixing different SES students within an entire school. Current evidence generally neither supports nor denies the existence of peer effects in secondary schools. Evidence from research on within-classroom groupings in primary schools indicates that the mixing of children within primary classrooms raises performance for low SES children more than it lowers performance for high SES children. The correlational evidence from large statistical analysis does not consistently suggest that higher parental SES or more affluent neighbours tend to increase the cognitive ability or academic achievement of children.

Research gaps

Given that New Zealand's school reforms have features such as a combination of decentralisation of control and largely centralised funding, competition and choice, and a lack of zoning, the reviewers suggested research on topics such as the impact of decentralisation of control on the variety of schools and approaches within schools, whether the introduction of competition has fulfilled its promise, and brought any unintended consequences, and how the policy of reviving Maori language and culture in part though the schools leads to improved life success for Maori children. 
Early Childhood Education Literature Review, by Anne Smith, Grace Grima, Michael Gaffney, and Kim Powell, from the Children's Issues Centre, University of Otago.

This review covered the most recent literature on early childhood education (ECE), including centre-based, home-based and home visiting early childhood services, from birth to starting school. It addressed three areas: learning and developmental outcomes, ECE's contribution to social cohesion, and participation benefits to parents. The review defined the term ECE as education and care and included home-based and centre-based early childhood programmes for children from birth to five years of age. It used an ecological perspective, emphasising that development is affected by a range of contexts, both children's immediate contexts of home, early childhood centre or neighbourhood, and the contexts beyond them. Those contexts also influence how caregivers and teachers interact with children.

\section{Participation}

The review found New Zealand children had a relatively high participation (56-60\%) in a variety of early childhood programmes, but their level of participation was generally for a small number of hours. An increase in attendance between 1990 and 1998 was largely due to increases in the enrolments in childcare centres. A number of ECE programmes are low cost both to families and the state. Children of European background are more likely to attend an early childhood programme than children of Maori or Pacific Nations background. Barriers for Maori participation were mainly cost and lack of transport and information. Families of low SES and low income, and families in rural areas, were less likely to have their children in ECE.

Some research evidence showed that earlier, longer, and more intensive participation in ECE was likely to be more effective on outcomes, and that a sizeable minority of children's arrangements did not meet parents' preferences in terms of hours. Other barriers to children's participation included cost, lack of transport and lack of information. The reviewers found there had been a resurgence of interest in the importance of the first three years of life for the healthy development of a child's brain. The review discussed some of the issues in the neuroscience debates in relation to early brain development.

Effects of ECE

The authors noted that the effects of ECE were difficult to discuss without considering the influence of family backgrounds. International studies indicated that participation in high-quality ECE programmes contributed to both short- and long-term gains in performance for disadvantaged children, and that ECE participation can narrow the gaps in achievement between different groups. In New Zealand, ECE was found to have positive effects on children's competency levels. Attendance at ECE programmes was associated with cognitive gains and improved performance in school throughout the world. Social gains were reported mainly from intervention studies with high-riskchildren, but the ECE experience could help all children develop social competencies. ECE experience tended to be a stronger force in lives of low-income children than middle class children.

\section{Quality}

There are many different perspectives on the nature of quality ECE, so defining quality involves negotiation and argument between stakeholders, and balancing of multiple perspectives. Children are relatively powerful stakeholders whose perspectives and rights should be considered in defining quality. Evidence on the structural and process effects of quality should be taken into account in determining what ECE contexts encourage the fullest development of children's talents. There is evidence that quality processes support children's development, and these include sensitive and responsive interactions and relationships between staff and children; curriculum and programme planning (and an emphasis on children learning, not just custodial care); peer group harmony; and communication with, and sensitivity to, parents/whanau. Structural quality has also been shown to have an impact on child development outcomes, including adult-child ratio; group size; staff training, education and experience; staff wages and working conditions; and staff stability.

Family outcomes

Some research indicated that economic policies and childcare support programmes had to be flexible to be appropriate for families with diverse needs. Economic disadvantage may result for families of low SES when the policies (e.g., eligibility for economic and childcare assistance) were not flexible enough for them. The availability of ECE could have both positive and negative effects on family psychological well-being, family relationships, and family functioning. The literature showed clear indicators of quality for successful outcomes in approaches to early childhood programmes which used parent 
education, particularly with a partnership between the programme providers and families.

\section{ECE policies}

Access, affordability, work schedules and current income level all created different needs for working mothers and their families. An open market was likely to encourage parents to under-invest in their children's ECE. As early childhood policies tend to be designed to meet a range of societal goals there could be a tendency for the policies to lose their coherency if potentially conflicting goals were involved. Some research indicated that parents did not always choose the best quality ECE for their children, and many tended to be satisfied with whatever programme their children were participating in. Hence, leaving the determination of quality to parental choice was not a useful policy.

Gaps

One of the greatest gaps was in the area of determining the outcomes of early childhood education on families and social cohesion. There is a need for further policy research, through comparative policy studies that highlight different international approaches. Different paradigms are needed, along with multi-method approaches to examine the long-term effects of different types of ECE provision, and to disentangle the effects of individual characteristics from the contribution of early childhood settings. Evaluations of the impact of new policies are needed. There is a also a need for research which examines a variety of early childhood cultural contexts, and continuities and discontinuities between home and early childhood setting to illuminate different participation rates according to ethnicity and socioeconomic status.

The Effects of Curricula and Assessment on Pedagogical Approaches and on Educational Outcomes, by Malcolm Carr, Clive McGee, Alister Jones, Elizabeth McKinley, Beverley Bell, Hugh Barr, and Tina Simpson, at the University of Waikato.

This review outlined the impact of curriculum, pedagogical approaches, and assessment regimes on education and social outcomes.

\section{Curriculum}

According to the reviewers, no firm research-based conclusions can be drawn as to whether a curriculum should be mandated or open at the national level, or about the level of specificity of learning outcomes that should be defined. There is no clear evidence that the existence or absence of a national curriculum leads to improved student performance. All OECD countries, including those high-performing countries in TIMSS (The Third International Mathematics and Science Study) are revising their curricula to include more practical work, relevance, and motivation. Progression is one of the least understood areas, yet is crucial for designing curriculum and enhancing student achievement. Research is lacking on the complexity of curriculum, assessment, and pedagogy and its influence on student achievement in the classroom. Evidence shows that when critical thinking skills and content are included in a school curriculum student performance can be raised.

\section{Assessment}

Research indicated noidentified correlational or causative link between increased summative assessment and increased learning outcomes. There is a positive relationship between increased formative assessment and increased learning outcomes, although summative assessment can dominate in classrooms, resulting in fewer opportunities for formative assessment. Assessment approaches impact strongly on pedagogy, both on teaching and content. Assessment in the classroom was seen as being more systematic, more purposeful, better recorded, and was discussed more by the teachers, when lesson or unit planning involved more consideration of the assessment of learning outcomes. The effect was also seen as positive if the learning outcomes matched teachers' convictions and goals of education.

High stakes national testing and monitoring can create distortions of the mandated curriculum objectives when memorisation of facts and displays of basic skills are promoted, rather than higher levels of learning and skills which can be assessed through performance tasks. Research on high stakes national assessment has indicated an increase in, for example, "teaching to the test", a more restricted pedagogy and curriculum, and more subject-based and whole class teaching.

Research is lacking on the advantages and disadvantages of different forms of assessment tasks on student learning outcomes. There is little, if any, research (particularly in New Zealand) on whether national testing and other accountability measures promote education change or development. No research findings on assessment activities which would provide valid, reliable, trustworthy, and fair information about Maori, Pacific Nations or other minority students were found in the review. 
Pedagogy

The role of the teacher is central to research on pedagogy, given the intervening role of the teacher in the classroom. Research on pedagogical practice provides information about characteristics of effective teaching, such as having a broad understanding of curriculum aims and objectives; a wide range of pedagogical strategies, high expectations of all students, knowing students well, providing good feedback to students, recognising student success, sound content knowledge, and taking responsibility for students' progress. Findings on successful teachers of culturally different groups centre on attitudes. Successful teachers were found to have high academic expectations of students, respect the diversity these students bring to classrooms, engage with their knowledge and experiences, use a pedagogy that is student centred, and are aware of their role in teacher/student/ community relationships.

It is difficult to quantify teacher effectiveness, since decision-making about pedagogical strategies in classrooms is a complex professional response to many factors. A key finding was that learning outcomes are enhanced by teachers with an understanding of conceptual and procedural development in the related subject area.

Low knowledge levels restrict classroom practices and learning opportunities for students. Conclusions about class size and organisational factors are tentative: class size may not necessarily change pedagogical styles of teachers; the research on class organisation regarding streaming and integration is inconclusive; the way teaching is organised is inseparable from the way teaching is carried out; pedagogical practice is more deeply held than is often credited; the research is inconclusive as regards grouping in classes; and resources, including human resources, do affect achievement.

Interactions among curriculum, assessment and pedagogy

It was found that the more specified the curriculum, and the higher the stakes associated with linked summative assessment processes, the more likely that restricted pedagogical approaches with a focus on fragmented and rote learning will occur. Learning achievements can follow when there is specification of sufficient detail to help teachers guide student learning, with clear indications of how subject material should be structured. Major reviews of formative assessment provide strong indications of significant learning gains. There was broad agreement in the literature surveyed that teaching approaches which begin with high expectations of students, contain high levels of work-related talk and discussion, and build from students' existing knowledge contribute positively to learning enhancement.

Gaps

A research gap of particular relevance to New Zealand is the lack of attention to curriculum, assessment and pedagogy issues relating to Maori education. Other topics include teacher change with respect to a socio-cultural framework, cross-cultural interpersonal relationships, and research in education and te reo Maori. A programme of classroom-based longitudinal research would contribute to better understanding of educational issues facing Pacific students and other groups, since they would no longer be invisible in the wider picture.

Research on what actually happens in classrooms (rather than reports about it from participants), and on formative assessment, is needed. There appears to be a lack of research in classrooms indicating the advantages and disadvantages of different forms of assessment tasks on student learning outcomes. More classroom research is needed on the interaction between curriculum, assessment, and student achievement. If curriculum reforms and assessment reforms take place at the same time, how much change is due to each variable is unknown and will need further exploration.

Issues to be explored in relation to the New Zealand Curriculum Framework include the relationship between official curricula and the implemented classroom curricula, and the relationship between progressions defined in curricula and the actual learning progressions in the classroom. The overwhelming evidence from this review is that, given the central role of the teacher in the classroom, research which illuminates the significance of teachers is imperative.

The Effects of School Governance, Ownership, Organisation and Management on Educational Outcomes, by John Rentoul and John Rosanowski, from Christchurch College of Education, with Neil Dempster (Griffith University, Australia), Darrell Fisher (Curtin University, Australia), Neville Hosking(Eastern Washington University, USA), Roger Hunter (Griffith University, Australia), Geoff Pugh (University of Staffordshire, UK), and Geoffrey Walford (Oxford University, UK).

This review focused on models of governance, ownership, organisation and management (GOOM) and their effects on educational outcomes 
at both the school and classroom level.

Most GOOM literature is "painted with a broader brush". It is concerned with trends in governance at the national, state, or district level that impact on school GOOM. Legislated governance initiatives in most countries have resulted in reform and restructuring to meet the current political and socio-economic imperatives. School improvement programmes are potentially useful for improving educational outcomes for students. From the research evidence cited, this review showed that, compared to the role of the teacher, GOOM does not necessarily have a powerful influence on student educational outcomes.

School-based management

The review noted that school GOOM reforms were informed internationally by an emphasis upon managerialism and a market-based approach, with varied degrees of implementation dependent upon different national systems, and a heightened emphasis upon examination results and test scores. The review focused mainly on school-based management/governance, but there was little empirical evidence of a direct causal link between school self-governance and improved student outcomes. The literature on different types of schools in different countries (e.g., site-based management, grant-maintained schools and city technology colleges in England/Wales, and charter schools, contract schools and for-profit schools in the USA) was reviewed. Some positive indirect effects on educational outcomes, such as a sense of empowerment among stakeholders, and increased teacher involvement among key players, were found. However, it has been suggested that school-based management may be a necessary but not a sufficient factor in improving student learning and achievement.

Overall, few studies have attempted to measure the differential effects of GOOM components in educational outcomes. Studies measuring differential outcomes have proved to be inconclusive. There are few empirical studies of GOOM and its effects either at the school level or at the classroom level, with minimal evidence of a direct causal relationship between self-management and improved outcomes.

School choice

The review noted that public choice theory has inspired a legislatively endorsed move towards the marketisation of schooling, through policies such as open enrolment, and different governance and ownership models. The impact of school choice in England/Wales, the USA (with charter, magnet and full-service schools) and Australia (different varieties of secondary school provision) was examined. However, there is little conclusive evidence about the effects of school choice on student achievement, or of superior educational outcomes for any particular governance or ownership model.

School effectiveness and school improvement

The review also examined the literature on school accountability and performance, and the impact on student achievement, but there appears to have been no consequential change in student achievement. Studies from the school effectiveness research movement (concerned with identifying correlates in order to determine school effects), and school improvement research (in particular focussing upon the dynamics of the change process in a school) were reviewed, but although some gains in student achievement are purported to have occurred, the evidence is inconclusive.

Gaps

Gaps in the research literature include the need for a range of methods, such as generalised cause-effect research, and longitudinal in-depth qualitative studies of a selection of various types of schools in New Zealand, with studies using a range of pre-post designs, multi-level modelling, survey and ethnographic techniques if explanatory links between aspects of GOOM and student outcomes are to be either confirmed or rejected. There is also the need to investigate more rigorously any perceived links between systemic reform and school reform, and between school reform and classroom reform. Other potential research topics were suggested, such as Maori ownership or governance models, how practices of ownership and management give rise to compositional (school mix) effects, the impact of networks - such as kura kaupapa Maori, and the Strengthening Education in Mangere and Otara Schooling Improvement Project (SEMO) - on governance/ management, different models of ownership, such as partnerships among clusters of schools, and whether different models of GOOMlead to more or less equality of student outcomes.

The Effect of School Resourcing on Education Outcomes, by Norton, P., Sanderson, K., Booth, T. and Stroombergen, A., from BERL/Infometrics.

This review focused on the theoretical and empirical literature on the relationship between school resources and students' education outcomes, in particular, the effect of different levels and/or types of 
school resourcing on students' education outcomes, how different approaches to delivering school resources impact on students' education outcomes, and research on the effect of different performance incentive systems on the education outcomes of students.

\section{Production function theory}

This review was based on the production function theory to discuss the effect of school resourcing on education outcomes. Because school resources were determined by many of the same factors that affect student performance directly, it was difficult to isolate their effects. This complexity demanded an organising framework which depicted the relationships between all of the variables (inputs and outputs) and which led to a mathematical specification that was amenable to analysis; typically but not always econometric analysis. At the centre was a "production function" which related inputs such as funding method, teacher quality and so on, to outputs such as test scores and incomes.

Effects of resources

The reviewers concluded that additional education had a positive effect on test scores and incomes. However, studies had different indications as to the magnitude of the effect. The effect on incomes or test scores of an additional year of education was probably around 6-8 percent, and certainly less than 10 percent. Literature on quantity of education was typically not concerned about whether the increase in the quantity of education resulted from a direct increase in resources or from an improvement in the way existing resources were employed.

Quality of education used measures of resources as a substitute for the unobservable "quality" variable. Four commonly used measures were teacher-student ratios, class size, teacher salary, and per-student funding. However, the reviewers noted that these measures might not be able to represent the complexity of the education process. Teacher-student ratios showed no consistent effect on educational outcomes on test scores and future earnings. However, class size had a bearing on test scores, particularly for lower-achieving students. For a reduction in class size of 5 students test scores could improve by 0.2 of a standard deviation. Teacher salary was found to have a negligible impact on test scores, but a positive effect on future earnings. Per-student funding appeared to be positively and significantly related to future incomes.

The reviewers stressed that there were factors over which the school had little or no control, such as student SES and ability. In addition, income was affected by other variables determined by the local labour market. It was therefore more difficult to relate school resources to income than to relate them to test scores. Most economists would contend, however, that income was a better measure of school quality than were test scores.

In most educational jurisdictions, cost economies per student were largely achieved by rolls of 600-800 students, with little cost reduction above this. In high schools a roll of 400 could provide an adequate curriculum and a roll of 800 could provide an extensive curriculum. The optimal high school size was reported to be in the range 400-1000, with 600 about the ideal size. Learning gains in schools smaller than 600 were more equitable, although the average gain was lower. The ideal size of school applied to low and high SES schools, and for schools with low and high minority concentrations.

Equity

Equity in educational funding may be seen either from the perspective of the student or from the perspective of the taxpayer. Equity for students needs to consider the requirements of students with special needs. Research showed clearly that funding regimes should take factors such as student ability and socio-economic background into account. Based on the traditional production function, schools with similar funding and similar students in terms of ability and socio-economic background could be expected to produce similar outputs. However, research evidence showed that it was not the case. Some schools used their resources more effectively than others, as they had better leadership, pedagogy, and school cultures.

New Zealand's funding system, being based on SES deciles, allocates proportionally greater funds to lower SES schools on the assumption that these schools required more funds per student to bring their performance up to national academic standards. However, the reviewers suggested that this objective has not been achieved, as the criteria on which the SES deciles were calculated have not, in their view, been tested for their empirical relevance to specific measures of educational attainment.

Delivery of resources

Research on different approaches to delivering school resources showed divergent views, for example, in the contention that the allocation of school budgets between the major categories of school resources did not differ much between direct or central resourcing. However, more 
fine-grained analysis indicated that more specialist staff were employed in directly resourced schools, and it was felt that these staff were contributing to improved student outcomes.

The evidence on the success or otherwise of voucher schemes was mixed. The literature suggested some marginal private benefits. It increased the incentive for families in higher SES groups to move to more low-income communities in order to qualify for the scheme. This increased competition amongst schools and was likely to weaken unionisation, which had a negative effect on school quality.

Research on whether private schools showed higher achievement than public schools has always been ambivalent. In some cases there was evidence for higher achievement for students attending private schools, but in others the differences were minimal or zero.

Gaps

A key problem with estimating production functions was the lack of good measures of both inputs and outputs. The process by which the inputs were combined was likely to be at least as important as the level and type of the resource inputs. Unfortunately factors in the process were not easily quantified, but they illustrated where econometric analysis was likely to encounter difficulties. The success of the production function approach may hinge on how well it can be adapted to capture educational processes. Although incomes and test scores were reasonably well measured, the wider societal and non-market outcomes were less easy to quantify. The reviewers suggested that research in school resourcing also occurred in fields such as political science, sociology, psychology, and education. These areas were generally more concerned with test scores as the outcome measure rather than earnings or educational qualification. The broader social benefits of an educated person were rarely addressed in this area.

Human Resource Issues in Education: A Literature Review, by Michael Fullan and Blair Mascall, Ontario Institute for Studies in Education, University of Toronto.

The review examined various parts of the human resource strategy teacher recruitment and preservice training, hiring and induction, professional development, and standards and assessments for teachers and principals. The reviewers used a model whereby they placed "the learning profession" in the centre of four interlinking circles (hiring and induction; professional development; preservice training; standards and assessment), all of which were in two layers (structures and mechanisms relating to policies and incentives).

This literature review was undertaken to gain an understanding of human resource issues in education around the world. The reviewers' intent was to gather material which gave a sense of the variety of practices in place in various jurisdictions. Wherever possible the reviewers searched for empirical evidence of the relationship between investments and outcomes. They discovered there was limited empirical evidence to be found. Instead, the vast majority of the research was qualitative, giving an understanding of cases where a particular approach works.

The rationale for placing the learning profession in the centre is that this label is more than an abstract term. The reviewers state that today's "knowledge society" requires a teaching and principal workforce capable of learning on a continuous basis. There is a need to identify the particular demographic, economic, social, and political circumstances facing societies in the year 2000 and beyond. In this context, the values, motivation, and capacity of educators will be the key resource for the educational system.

\section{Teacher education}

Many jurisdictions around the world have been dealing with a shortage of people entering the teaching profession. The challenge is to attract a high number of applicants, and to ensure that the qualifications of the applicants are sufficiently high to meet the standards of the profession. Teacher shortage was highest in inner cities and areas of rapid growth, in the United States; low salaries were a factor; the perceived status of the profession had a considerable impact on its appeal; and there was increasing concern about a shortage of principals.

Teacher expertise accounted for a large variation in student achievement, and teacher education, and teacher ability, along with small schools and lower teacher/student ratios, was associated with significant increases in student achievement. Teachers often consider themselves inadequately prepared by their pre-service programmes. Many teachers feel that the quality of teacher supervision in their placements is not what it should be.

The reviewers asked "What should a strong teacher education programme look like? Case studies found six common features: a common clear vision of good teaching reflected in course work and clinical experiences; a curriculum grounded in knowledge of child and 
adolescent development, learning theory/motivations, and subject matter pedagogy; extended clinical experiences; well-defined standards of practice used to guide and evaluate work; strong relationships, common knowledge and shared beliefs among school and university-based faculty; extensive use of case study methods, teacher research performance and portfolio evaluation applied to real situations.

Retention

One United States study found that at least 30 percent of new teachers left within five years of entry. An Australian study found inadequate induction programmes were responsible for high attrition rates (a particular problem in rural areas, and a concern for new Aboriginal teachers). The cost of attrition is acute, both in the hiring process itself and in the dearth of experienced teachers who can provide leadership in schools. Hiring practices vary primarily as a function of the balance between centralised and decentralised systems. Where highly centralised systems generally have a large pool of talent on permanent contracts from which to draw, they are often characterised as inflexible, highly unionised, and having overly bureaucratic processes. In contrast, decentralised systems (generally school-based) have great flexibility, and are able to hire for their specific needs, but may have to draw on a small pool of talent that may not meet their needs. Studies in the United States suggest that much of the problem of teacher shortages could be solved with improvements to the hiring process. This is particularly true in subject areas where there have been shortages over many years, such as science and mathematics.

While there are many different approaches to teacher orientation or induction, there is little systematic research to evaluate the benefits of such programmes. Programmes with training and support for mentors, and specific support components for new teachers do make a significant difference with respect to whether teachers stay in teaching in the first critical years. The reviewers concluded from some Australian research that the most important factor in successful induction is the quality of the mentors.

Regulation of teaching profession

The reviewers regard the call for teachers to be licensed to meet particular standards as part of a political movement of accountability. Teachers are seen as public servants who should be accountable for their work to the public at large. The argument from the politicians in the United States is that setting standards for teachers will improve student performance. The parallel argument for setting standards, coming from practitioners, is that standards are an essential element in improving the abilities of teachers, and in proving to society that teachers are to be trusted and respected.

There has been a considerable increase in teacher testing in the 1980s and 1990s in the United States, and a trend seen in recent Australian state initiatives. Research into these initiatives suggests that while teachers require basic knowledge, a written test is not an effective method of assessing such knowledge. Moreover, tests of basic skills are not good measures of teaching abilities, or capable of identifying individuals who will be good teachers. The reviewers described ways of evaluating teachers beyond "paper and pencil" tests, for example the PRAXIS series created by the National Teacher Examination produced by the Educational Testing Service; and the framework developed by the National Board for Professional Teaching Standards, both in the United States. Research on the effects of these frameworks suggests that the process of attempting certification has had a significant effect on the work of the teachers involved. Participants find that the licensing or certification process challenges and stimulates their practice in a very productive way.

Research in the area of recertification and performance-based compensation has shown that individual merit pay, career ladders and similar schemes have often failed. The reviewers believe emerging evidence points to building a system of standards-based assessment and corresponding professional development for beginning teachers, "threshold" teachers (for example, after seven years), and experienced teachers. Forms of teacher compensation would be linked to the scheme. Individual principals are often the key agents of school success.

Professional development issues

Professional development is key to the success of any reform initiative, provided that it is linked to ongoing learning of individuals, and to school improvement, and to related policy and programme implementation. Characteristics of effective professional development were noted, such as focusing on concrete classroom applications of general ideas, and involving deliberate evaluation and feedback by skilled practitioners. The symbiotic relationship between professional development and school improvement is a persistent finding. School improvement cannot occur without a closely connected culture of professional development. 
Research has provided evidence on the relationship between professional community and student performance. The reviewers outlined what constituted a "high professional community". Schools that succeed against the odds are led by very effective principals, although the results cannot be explained entirely by particular policies, training, or credentials. A number of systems are developing professional networks and partnerships to promote collaboration for educators. They are organised around teaching methodology, subject matter, or school improvement initiatives. Four common features of professional networks have been identified: they have a clear focus and target a specific component of the community; they offer a variety of activities, providing choice; they create a discourse community of "critical friends" for reflection and debate; and they contribute to the development of leadership skills.

Gaps

Implications for policy and research were raised, in order to provide a context for policy frameworks to meet the needs of New Zealand students and educators. Further research is needed on teacher recruitment and pre-service training (e.g., establishing a set of standards for what teachers should know and be able to do, implementing assessment mechanisms, developing standards for teacher education programmes); hiring and induction; professional development; standards and assessment for teachers and principals; and the nature of the learning community.

Quality in Tertiary Education: The Literature, by Education Directions Ltd.

This review focused on the literature on quality in tertiary education, particularly on how quality relates to public policy, rather than how quality is promoted and assured within education and training organisations.

\section{Defining quality}

Quality in tertiary education has become an increasingly important issue over the last two decades, as changes in the nature and scope of tertiary education have brought pressure to bear upon traditional notions of what constitutes quality in tertiary education and training. Any debate or attempt to plan for quality assurance or quality measurement raises the question of the definition or purpose of tertiary education itself, and who should define it. The reviewers note there was much more research on how tertiary education models could work, than there was research on how tertiary education models did work.

Quality for the review was defined as "fitness for purpose". Research under the Quality in Higher Education (QHE) project provides a useful benchmark. This large scale examination of the definition of quality by various groups suggested there is no single correct definition of quality. This project identified a number of assessment criteria, including: adequate physical resources (library, workshops, IT) and human resources (properly qualified staff) to support teaching and learning; programmes with clear aims and objectives that are understood by staff and students, and well-related subject content; students encouraged to be actively involved in, and given responsibility for, learning; the standard of the programme appropriate to the award; and valid, objective and fair assessment, covering the full range of course aims and objectives, with students receiving useful feedback. Other studies focused on identifying specific criteria for judging the quality of teaching and learning.

There appears to be a level of agreement on a number of the criteria of what constitutes quality in tertiary education. The main factors relating to the effectiveness of teaching were respect for students, organisation in delivery and the provision of challenge in learning, and setting high but realistic goals for students.

Measuring quality

Quality can be measured in relation to inputs, processes, outputs and/ or outcomes. There are also a wide variety of measurement methods. They includes the use of quantitative or qualitative criteria and measurement approaches, methods which are focused retrospectively or prospectively, methods which measure absolute or relative quality, and measurement approaches which use criteria generated by those involved in an activity or by external groups. The research identifies issues such as who measures quality, what criteria are used, the source of the criteria, and the use made of measurements of quality, as all being of importance in exacerbating or easing this tension. The issue of productivity is related to that of quality, in that overall levels of research productivity are used as measures of the "quality" of researchers and departments, and because of the impact productivity may have on the quality of research output itself. 
Research on the measurement of the quality of qualifications and the programmes leading to them is relatively sparse. Most of the research relating to approaches to the measurement of the quality of "qualifications" in fact focuses on the quality of programmes and their delivery, rather than on the quality of qualifications per se.

Quality assurance

The literature has greater consensus with respect to approaches to assuring quality in tertiary education and the importance of external validation. There is relatively little published research covering internal quality assurance or its effectiveness, generally, let alone in tertiary education. External quality assurance focuses on accreditation, assessment, and audit. A key theme running through the literature was the level or extent of self-regulation and autonomy associated with each of these approaches.

The bulk of recent research on the impact of quality activities has focused on the impact of external quality assurance, rather than upon the impact of the measurement of quality or of internal quality assurance activities. A summary of studies reveals that external quality assurance has had a real impact on tertiary education in the countries studied, although identifying the extent to which changes are a direct impact of quality assurance activities is difficult.

One study did examine the issue of whether quality can be achieved or maintained despite resource constraints. The study examined four strategies that can maintain quality within an environment of constrained resources, including the introduction of a common first year curriculum, articulation, modularisation, and franchising.

Gaps

The reviewers identified a number of areas in which research literature is lacking, or where further research would be useful, including: identifying criteria for assessing quality deemed to be of importance to clients and stakeholders in New Zealand; testing whether criteria for assessing quality identified in international literature are relevant in the New Zealand context; research on the identification of the effectiveness of different performance indicators and measurement techniques for use in internal quality assurance; approaches to the measurement of quality by employers; approaches to the measurement of the quality of qualifications; the effect of different approaches to follow-up of quality assurance; the effect of sanctions in relation to quality assurance; and the effect of resourcing on quality.
Enterprise-based Education and Training: A Literature Review, by Michael Long, Rose Ryan, Gerald Burke, and Sonnie Hopkins, University of Monash, Australia.

The Ministry of Education wished to gain an understanding of the costs, processes, outcomes and benefits of work-based and "on-the-job" training and learning; and "off-the-job" training and learning. Literature in this review included general topics (such as the importance of human capital development in a developed economy, and how its role has changed over time; the extent to which employers consider training and education as a cost or an investment, and the nature of policies which have influenced this perception; productivity of training and education, and consequent improvement in people's flexibility. It also included work-based training and learning, formal "off-the-job" training, and government-subsidised job training.

This review focused on publications from 1993 onwards that presented and interpreted empirical research on the distribution and outcomes of enterprise-based education and training. The empirical evidence was interpreted in a broad sense and included a range of methodologies from refereed journals and papers from government agencies. The term "enterprise-based education and training" included study for a recognised qualification, formal training, and informal training. The reviewers distinguished it from initial education and training that may take place at the firm as part of the school-to-work transition.

Work-related training

The amount of work-related training undertaken by employed people was substantial in New Zealand (the equivalent of two years of schooling per employee). The increasing interest in enterprise-based education and training resulted from long-term structural changes in the nature of the labour force and economic activity. These changes included the continuing shift away from agriculture and manufacturing to the service industries, the changing occupational profile of the workforce, the greater importance of international trade, the importance of technology in production, and the increasing uncertainty over stable full-time employment.

The literature showed substantial diversity of the direction and size of the correlates of training across countries. Workers in favourable positions in the labour market (largely professionals or managers, with high salaries, full-time employment, high levels of educational 
attainment, and not from an ethnic minority) received more employer-supported education and training than other workers. Some types of enterprises were more likely to provide training for their workers: large workplaces; enterprises in the finance insurance and business services industry and in the community, social and personal services industry; public sector enterprises; and those with high levels of technology. There was some indication that women received lower levels of employer-supported education and training, but this was not always consistent. In addition, the evidence about the direction of the relationship of tenure with receipt of training was very mixed. Similarly, results about the relationship between the competitive environment of an enterprise and the level of training it provided were not clear.

Effects of training

Training increased wages by an average of about 8 percent, but the size of the effect varied between studies. General training had larger wage effects than specific training, and longer courses produced larger wage effects. Formal training showed larger effects than informal training, and off-the-job training had larger effects than on-the-job training. Employer-supported training had a larger effect than non-employer supported training. There was some (contestable) evidence that the training of workers with a lower probability of receiving training did not have higher wage effects.

Flexible workplaces were often contrasted with assembly-line production. These workplaces were more likely to be present in larger companies in the manufacturingindustry. Human resource practices of workplaces provided an important context within which training operated; any effect of training was likely to be mediated by those practices. The literature pointed to positive outcomes associated with the adoption of flexible workplace strategies.

The reviewers noted that rates of return to training expressed the benefits of employer-supported education and training as a percentage of costs, given certain assumptions about the flow of costs and benefits over time. Little information was available about the rates of return to employer-supported education and training.

Financing training

The classic theory of the financing of industrial training is based on a distinction between general training (useful to many firms) and specific training (useful to only one firm). Employees should pay for general training and enterprises should cover specific training. However, several observations undermined the classic approach to financing: the mechanism by which employees were thought to pay for their training was the acceptance of a lower training wage; there was little empirical evidence of a training wage; and enterprises did in fact pay for a substantial amount of training that was useful to other enterprises. Some researchers proposed various mechanisms that would insulate enterprises against the risk of losing newly trained workers to other enterprises. However, there was little evidence about the relative size of their effects. As a result, there was an acceptance that employers tended to provide less than the socially optimal amount of training.

The reviewers discussed two scenarios that might influence the extent of benefits from the provision of greater amounts of firm-based education and training. There is the possibility that declining returns from additional training for those workers who already receive some training sets a limit to further investment by firms in training. There is also the possibility that workers with a low probability of receipt of training might show greater benefits from training. However, the evidence proposed in favour of this latter position was not considered conclusive. Considerations of comparative advantage suggest that workers who received training may do so because they are deemed more suitable. It was noted that information on workers' and employers' perceptions of the need for training may provide insight into possible areas of skill shortage, but the evidence needed to be treated with caution.

Industry training in New Zealand

Industry training in New Zealand underwent a significant degree of change in the early 1990s, through the establishment of the National Qualifications Framework (NQF) and provision of the Industry Training Act. The intent of the policy was to encourage a greater extent and incidence of industry training. Government subsidised approved training by individual enterprises through the Industry Training Fund (ITF) and also purchased training directly from private Training Establishments. In this respect, it mirrors various policy initiatives from different countries designed to increase the level of training provided to workers: training levies, training grants, training loans, the Investors in People Standard developed in the UK in 1990, industrial agreements and schemes for workers. Research on the benefits of different types of training is needed to determine whether, and in what ways, they do increase workers' skills and productivity. 
Influence of Peer Effects on Learning Outcomes: A Review of the Literature, by Ian A. G. Wilkinson, John A. Hattie, Judy M. Parr, Michael A. R. Townsend, from the University of Auckland, and Martin Thrupp (University of Waikato), and Hugh Lauder and Tony Robinson (University of Bath).

This report presented a literature review and conceptual model summarising the influence of peer effects on student learning outcomes. Its purpose was to gain a better understanding of the existence, strength and influence of peer effects (defined as the influences of student-to-student interactions and group dynamics on student learning outcomes). This research report was important to the Ministry, given that assumptions about peer effects may influence schools' streaming or tracking policies, parents' residential and school choice decisions, students' choice of subjects, and government policies on school enrolment, zoning or transport.

Model of peer effects

The authors propose a multi-layered model, with effects propagating from school-level influences, to class-level influences, to group-level influences, to surrounding structured environments for learning among peers. It is proposed that the bulk of the effects are indirect. Peer effects "look" smaller the further away they are from the instructional "coalface" because they are mediated by intervening layers. Although there may be reciprocal effects whereby peers influence teachers and school organisation and management, the magnitude of these effects is unclear. Together with the three layers of influence, family resources appear to have greater effects at upper layers and smaller effects at lower layers; conversely, curriculum and teaching resources have greater effects at lower layers and smaller effects at upper layers. Home and school supports for learning carry the lion's share of the weight in predicting student learning outcomes, whereas peer effects, as currently constituted, carry much less weight.

Types of peer effects

The literature review showed that peer effects are greatest within the classroom, and become smaller at the more distant layers of the whole school and school community. At the within-class group level, there is a small but meaningful advantage of grouping students for instruction as opposed to using whole-class instruction. There is a small advantage of homogeneous over heterogeneous grouping within classes though this result depends upon the curriculum area and tasks. There is also a risk that lower ability students' learning may suffer in homogeneous ability groups, not only from less instruction and less effective instruction but from norms of behaviour that are not conducive to learning. At the class level, the nature and quality of instruction are more important than streaming, class size, or whether classes are composite or single-level, coeducational or single-sex.

At the school level, composition of student intake only accounts for a small amount of variance in student achievement - but many studies have not investigated the complexity involved in understanding school composition effects, so not enough is known yet about how these effects might operate through the processes of schooling. Students appear to benefit from attending smaller high schools (i.e., under 800 students) as they appear to provide a more equitable learning environment.

The findings from this evaluation have confirmed that the nature of the learning environment and the quality of instruction are more important than the impact of peers on students' achievement. However, educational policies and practices aimed at improving student achievement can take account of how peer effects operate. A variety of innovative, collaborative approaches to instruction that capitalise on peer effects have been demonstrated to improve student learning.

Gaps

There is a need to establish the relative magnitude of peer effects on learning across various learning environments, and the causal structures that lead to learning in these environments. At the group level, there is need for research that examines group characteristics (e.g., heterogeneous versus homogeneous ability composition) in relation to student participation, the nature of instruction, and students' learning outcomes. There is also need for research on the interaction and learning of students of different ethnic backgrounds in New Zealand, when engaged in co-operative work. At the class level, streaming and its impact, especially on students in lower streams, needs to be researched. Before implementing a class-level change, it may also be valuable to research the effects of various professional development programmes in order to optimise the possible benefits of the change in class composition At the school level, more research is needed on the effects of school composition and school size. 


\section{Key Findings From the Literature Reviews}

Ministry of Education officials examined and synthesised the findings from the literature review. The following summative statements reflect themes which were apparent in the literature reviews, and for which the evidence appeared to be very strong. A number of findings were reinforced by more than one literature review, and reflect an emerging consensus. It is important to recognise that reducing an expansive series of reviews and findings to a series of short statements does not do credit to the breadth and depth of the findings. However, within the Ministry, research and policy staff have found the reviews to be helpful in furthering their thinking about research priorities and in reaching consensus about key conclusions across all of the literature reviews.

\section{Teaching and learning DO matter}

Individual educators are far more important than has often been acknowledged. For example, in the school sector, as a rule of thumb, teachers contribute to about 40 percent of the variance in achievement outcomes, while schools contribute to about 16 percent of this variance. This is, in part, because classroom cultures and norms are shaped and experienced by teachers differently, and students are active participants in classroom dynamics.

\section{System level conditions are necessary but not sufficient to \\ improve outcomes}

Investments in system level infrastructure (for example, property, governance and management, new curriculum policies, or new technologies) can make a difference. However, such investment will be insignificant unless what educators do and how they improve their practice is central to policy development. Because system level policies are strongly influenced by within-institution (i.e., early childhood, school, and tertiary settings) and within-classroom factors, policy-makers may need to take more explicit account of how these factors influence the efficacy of system level change, and the capacity of the teaching workforce to respond to such changes.

Research is sparse on how teaching and learning are determined

Teaching and learning tend to have been researched in isolation, not as reciprocal processes. Research is needed to explain how educators' effectiveness varies depending on class composition, the curriculum area, and a variety of contextual and teacher factors. These factors include practices within educational settings, early childhood centres and schools with their community, access to, and the nature of, professional support.

\section{Early childhood education offers both short and long-term benefits to children}

While children, families and society experience general benefits, quality early childhood programme experience is a stronger force in the lives of low income children than in those of the middle class, and participation in quality programmes promotes children's competencies.

\section{The interaction between families and early childhood education and} schools is under-researched

Research indicates that outcomes are correlated with, not caused by, socio-economic factors. "Ability" is developed as children learn how to learn. The research tends to look at family and early childhood education and school influences on education outcomes in isolation. Furthermore, the research has not explored the less observable student, education setting, and family influences such as motivations, attitudes and decision-making processes which are thought to be causally linked to education outcomes.

\section{Little is known about the effects of informal workplace training}

This gap reflects a need for more accurate measures of training, as well as limited data on types of training recipients and the different training patterns within firms. Also, researchers have emphasised formal training more than informal training, possibly because it is amenable to government intervention, yet this accounts for only one third of all training in workplaces.

The complex interaction between social class, ethnicity and gender needs further exploration

Stratification appears at all levels of education where these three factors are compounded, but research is needed into how interaction patterns in early childhood and classroom settings are mediated by social class, ethnicity and gender, and how these patterns relate to learning.

\section{There are research limitations on measuring outcomes}

Outcomes often are identified only at a general level, obscuring significant differences within groups, regions or across learning areas. There are limited data about the influence of the quality of early 
childhood education and the early school years on children's competencies. Research on later school years tends to use indices of school attainment and income levels, rather than incorporating affective measures such as attitudes to learning and academic motivation.

\section{Looking ahead}

Since the completion of the literature reviews, the Ministry has been using them in a number of ways. In particular, they have made a significant contribution to identifying a set of potential research priorities. In late 2000, the Ministry drafted a set of draft strategic research priorities which represented a first major attempt to articulate and implement a forward looking strategic research agenda. These priorities synthesised the main research themes from the literature reviews, building on extensive cross-Ministry consultation and incorporating a range of strategic priorities for the Ministry itself. Members of the external research community were also consulted to get feedback on these research priorities.

The information on research priorities, research strengths, gaps and methods is an important resource for both the Ministry and the external research community. The Ministry is using this information to improve the quality of its strategic information base in two ways. First, it has set up a new cross-Ministry group to oversee a strategy for meeting its long-term information needs. The aim is to create better alignment between the Ministry's strategic direction, long-term policy questions, and all its analytical effort. As a second part of this process, the Ministry has also established some internal teams comprising policy, research and data analysis staff. These teams are exploring the best ways of building a knowledge base in particular areas over time - including primary or secondary research, new data generation, and the collection and use of results flowing out of programme evaluation.

\section{References}

Carr, M., McGee, C., Jones, A., McKinley, E., Bell, B., Barr, H., \& Simpson, T. (1999). The effects of curricula and assessment on pedagogical approaches and on educational outcomes. Wellington: Research Division, Ministry of Education.

Education Directions Ltd. (2000). Quality in tertiary education: The literature. Wellington: Research Division, Ministry of Education.

Fullan, M., \& Mascall, B. (2000). Human resource issues in education: A literature review. Wellington: Research Division, Ministry of Education.

Norton, P., Sanderson, K., Booth, T., \& Stroombergen, A. (2000). The effect of school resourcing on education outcomes. Wellington: Research Division, Ministry of Education.

Long, M., Ryan, R., Burke, G., \& Hopkins, S. (2000). Enterprise-based education and training: A literature review. Wellington: Research Division, Ministry of Education.

Nechyba, T., McEwan, P., \& Older-Aguilar, D. (1999). The impact of family and community resources on student outcomes: An assessment of the international literature. Wellington: Research Division, Ministry of Education.

Rentoul, J., \& Rosanowski, J. with Dempster, N., Fisher, D., Hosking, N., Hunter, R., Pugh, G., \& Walford, G. (2000). The effects of school governance, ownership, organisation and management on educational outcomes. Wellington: Research Division, Ministry of Education.

Smith, A., Grima G., Gaffney, M., \& Powell, K. (2000). Early childhood education literature review. Wellington: Research Division, Ministry of Education.

Wilkinson, I. A. G., Hattie, J. A., Parr, J. M., Townsend, M. A. R., Thrupp, M., Lauder, H., \& Robinson, T. (2000). Influence of peer effects on learning outcomes: a review of the literature. Wellington: Research Division, Ministry of Education.

\section{The authors}

The authors are all members of the Research and Evaluation (External) Unit of the Research Division, Ministry of Education.

David Philips was formerly a Senior Policy Analyst in the Learning and Evaluation Policy section of the Ministry of Education, with a particular interest in assessment policy and research. His PhD from Victoria University of Wellington was on policy importation and the development of the National Qualifications Framework.

Susannah Roddick's interest in research-policy links has seen her work as a policy analyst in the Medium Term Strategy Policy unit and do a $\mathrm{PhD}$ at the University of Canterbury in the political sociology of education, specifically the state's role in education.

Melissa Weenink has worked in a range of public sector agencies and has a particular interest in the relationship between public policy and research. She also holds a PhD in Sociology from Victoria University of Wellington. 